\title{
RESENHA
}

\section{FERREIRA, Roquinaldo Amaral. Cross-cultural exchange in the Atlantic World: Angola and Brazil during the Era of the Slave Trade. Cambridge: Cambridge University Press, 2012. 262 p.}

FABIANA SCHLEUMER

Universidade Federal de SÃo PAulo (UNIFESP/GuARULHos)

"A África e a formação do Mundo Atlântico" ${ }^{1}$, obra primordial para a expansão e o fortalecimento dos estudos sobre o Mundo Atlântico no Brasil, trouxe novas e importantes indagações. Abordou os aspectos cotidianos da vida dos africanos na África e nas sociedades coloniais do Atlântico, enfocando a cultura, a religião e as relações de trabalho. Posteriormente, Diáspora negra no Brasil, livro organizado pela historiadora Linda Heywood, prossegue as discussões sobre a África Central e suas relações com o Brasil ${ }^{2}$. Desde então, o campo dos estudos sobre o Mundo Atlântico tem crescido de modo significativo entre os pesquisadores brasileiros.

O livro Cross-cultural exchange in the Atlantic World: Angola and Brazil during the Era of the Slave Trade (2012), de Roquinaldo Amaral Ferreira, historiador brasileiro, Vasco da Gama Chair na Brown University e diretor associado do Center for the Study of Slavery and Justice, na mesma instituição, se alinha a esse debate: dialoga com a História e com a Historiografia do Mundo Atlântico, com especial atenção às relações entre Angola e Brasil.

É imperioso destacar a respeitável contribuição do autor para a temática. $\mathrm{Na}$ forma de artigos ${ }^{3}$ e capítulos de livros ${ }^{4}$, Ferreira tem participado de modo marcante no processo de reescrita da História de Angola e suas conexões atlânticas ${ }^{5}$. Em "Atlantic microhistories", o autor faz uso de informações

\footnotetext{
${ }^{1}$ THORNTON, John. A África e os africanos na formação do mundo atlântico: 1400-1800. Rio de Janeiro: Elsevier, 2004.

${ }^{2}$ HEYWOOD, Linda (Org.). Diáspora negra no Brasil. São Paulo: Contexto, 2008.

${ }^{3}$ Vale destacar: FERREIRA, Roquinaldo. Biografia como história social: o clã Ferreira Gomes e os mundos da escravização no Atlântico Sul. Vária História, Belo Horizonte, v. 29, n. 51, p. 679695, 2013.

${ }^{4}$ Vale destacar: FERREIRA, Roquinaldo. Slavery and the social and cultural landscapes of Luanda. In: CAÑIZERAS-Esguerra, Jorge; CHILD, Matt D.; SIDBURY, James. The black urban Atlantic in the age of the slave trade. Philadelphia, PA: University of Pennsylvania Press, 2013. p. $185-206$.

${ }^{5}$ Sobre a necessidade de reescrever a História de Angola, ver: HENRIQUES, Isabel de Castro. Presenças angolanas: os documentos escritos portugueses. In: Seminário Internacional sobre História de Angola, 2.; 1997, Luanda. Actas... Luanda: [s.n], 1997.
} 
biográficas para a reconstrução das microdinâmicas sociais, culturais e comerciais existentes em Angola no século XVIII e início do século XIX ${ }^{6}$.

Erigido sobre sólidos postulados historiográficos, o livro de Ferreira representa um avanço significativo no processo de reescrita da História de Angola e do Brasil, pois se distancia da visão factual, política e econômica, isto é, da concepção macro-histórica, presente na historiografia angolana. O autor procura, com base na micro-história, desvendar o cotidiano e as tensões de Angola na era do tráfico de escravos e o uso de fontes históricas existentes nos arquivos e nas bibliotecas de Angola conferem singularidade ao seu trabalho. Fartamente documentado, o autor não se detém em exaustivos debates historiográficos, mas se concentra na exploração de conjuntos documentais variados: cartas, ofícios, petições, certidões, requerimentos, relatos de missionários e processos inquisitoriais, permitindo que os elementos desse corpus dialoguem entre si.

Cross-cultural exchange in the Atlantic World está dividido em seis capítulos, distribuídos em 262 páginas, e faz parte da série African Studies, da Cambridge University Press. Cada capítulo apresenta ao leitor um personagem histórico a partir do qual o autor tece considerações sobre as relações entre Angola e Brasil. O livro divide-se em duas seções. A primeira abrange os três primeiros capítulos e tem como foco o estudo do tráfico itinerante feito por sertanejos e tumbeiros. Já a segunda, dos capítulos quatro a seis, atém-se às questões de caráter religioso, cultural e político.

No primeiro capítulo, "An expedition to the Kingdom of Holo", o personagem principal é Francisco Roque Souto, homem branco, que durante 22 anos serviu na Bahia como capitão de mar e desempenhou um papel importante na economia de Luanda. Assim como outros "homens de mar em fora", Francisco controlou o tráfico com os sertões e alcançou uma posição de destaque. Sua história é o ponto de partida para a compreensão do papel dos sertanejos e suas funções no tráfico itinerante angolano.

Em "Can vassals be enslaved?", o autor mantém o foco nas questões relacionadas ao tráfico sertanejo no interior de Angola, porém, detém-se no estudo dos africanos vassalos, que viviam em territórios onde o Soba era aliado dos portugueses. Além disso, discute os perigos do tráfico itinerante, bem como suas relações com os mercadores costeiros de Luanda e Benguela. Os tumbeiros e o impacto de suas estratégias de ação ganham destaque ao longo do texto.

No terceiro capítulo, "Tribunal de Mucanos", Ferreira relata a história dos escravos Jorge Inácio e Francisca, discutindo os frágeis limites entre a escravidão e a liberdade. O Tribunal dos Mucanos foi um espaço para o apelo à liberdade e à solução dos problemas cotidianos, fundamental para cativos e nascidos livres, tendo representado a possibilidade de mudança na condição de escravização, incorporando às suas funções, a partir de sua expansão no século XIX, o caráter punitivo.

\footnotetext{
${ }^{6}$ FERREIRA, Roquinaldo. Atlantic microhistories: mobility, personal ties and slaving in the black Atlantic World (Angola and Brazil). In: NARO, Nancy; SANSI, Roger; TREECE, David. Cultures of the Lusophone Atlantic. New York: Palgrave Macmillan, 2007. p. 99-128.
} 
Em "Slavery and society", Ferreira apresenta e discute a escravidão em Luanda e suas implicações. O censo de 1781 apontava que 52.329 indivíduos eram escravos, ou seja, metade da população. Para cada homem branco civil havia aproximadamente três escravos em condições de porte de arma. Luanda era uma cidade miscigenada, por onde perambulavam pedreiros, carpinteiros, caixeiros, alfaiates, costureiras e ferreiros, indivíduos e classes sociais que poderiam ser encontrados no espaço social das tabernas, locais de reunião de pessoas de diferentes níveis culturais. Ao mesmo tempo, o "lazer" era um espaço de inclusão e não diferenciação. As habitações permanentes configuravam-se como mecanismos de controle social, cabendo às populações locais morar em lugares afastados da região central. A expulsão dos sujeitos dos espaços centrais também fica demonstrada no tráfico com o Brasil, pois para cá foram enviados condenados por crimes como feitiçaria.

Já no quinto capítulo, "Religion and culture", Ferreira analisa, com cuidado e rigor, a história de Mariana: mulher negra, livre, viúva, nascida em Luanda, fluente em português e quimbundo, acusada pela Inquisição portuguesa de bruxaria. Segundo o autor, ela teria se envolvido afetivamente com Fernando Martins do Amaral, um soldado carioca, enviado a Luanda como degredado, por ter cometido um assassinato no Rio de Janeiro. Mariana foi acusada pela Inquisição portuguesa, entre outras coisas, de ter erigido um santuário para o demônio, e pode ser considerada uma "ganga", isto é, uma autoridade religiosa digna de poder e respeito em Luanda e Benguela. Durante, no mínimo, dez anos ela presidiu cerimônias religiosas, cerimônias estas que, de acordo com o autor, contestavam a ordem colonial. Tais cerimônias representam um exemplo das características do meio urbano em Luanda, onde a religião atravessou diversos estratos sociais, mantendo próximos não só os escravos e os negros fujões, mas também os distintos membros da elite local da época.

No capítulo final, "Echos of Brazil", Ferreira destaca as relações existentes entre Angola e Brasil, afirmando que não eram apenas de questões comerciais e culturais, pois os acontecimentos se revestem de uma dimensão política, e cita o processo de Independência do Brasil, em 1822, como um de seus pilares, um elo entre Benguela e Rio de Janeiro.

Por fim, no epílogo, "Rebalancing Atlantic History", o autor faz uma síntese dos debates e mudanças que, nos últimos vinte anos, têm norteado os estudos sobre o Mundo Atlântico e seus desdobramentos. Nesse contexto, merecem destaque os trabalhos desenvolvidos por Toby Green, James Sidbury e Jorge Cañizares-Esguerra.

Ferreira conclui o livro defendendo que, por meio da metodologia da micro-história e do conceito de Mundo Atlântico, é possível compreender e analisar a História de Angola e do Brasil para além das dimensões estanques que predominaram em suas respectivas historiografias.

Em suma, mostra-se urgente a tradução de Cross-cultural exchange in the Atlantic World. Precioso tanto na forma como no conteúdo, o livro de Ferreira constitui uma inovação nos estudos sobre o Mundo Atlântico, abordando novas questões, apontando caminhos e instigando reflexões. 


\section{Sobre a autora}

Fabiana Schleumer é professora adjunta de História da África na Universidade Federal de São Paulo (UNIFESP). Possui bacharelado(1995), licenciatura (1997), mestrado(1999) e doutorado(2005) em História Social pela Universidade de São Paulo (USP). Lidera o Grupo de Pesquisa "Trânsitos: dialogos culturais em África e na Diáspora" UNIFESP/CNPq. Coordena o GT Regional (São Paulo) de História da África da ANPUH (2014-2016).

Resenha recebida em 29 de janeiro de 2016.

Aprovado em 17 de junho de 2016. 